\title{
The simultaneous application of positive-end expiratory pressure with the Trendelenburg position minimizes respiratory fluctuations in internal jugular vein size
}

\author{
Sun Sook Han ${ }^{1}$, Woong Ki Han ${ }^{2}$, Dong Chan $\mathrm{Ko}^{1}$, and Sang Chul Lee ${ }^{2}$ \\ Department of Anesthesiology and Pain Medicine, ${ }^{1}$ Kangbuk Samsung Hospital, Sungkyunkwan University School of Medicine, \\ ${ }^{2}$ Seoul National University Hospital, Seoul National University College of Medicine, Seoul, Korea
}

Background: The respiratory cycle alters the size of the right internal jugular vein (RIJV). We assessed the changes in RIJV size during the respiratory cycle in patients under positive pressure ventilation. Moreover, we examined the effects of positive-end expiratory pressure (PEEP) and the Trendelenburg position on respiratory fluctuations.

Methods: A prospective study of 24 patients undergoing general endotracheal anesthesia was performed. Images of the RIJV were obtained in the supine position with no PEEP (baseline, S0) and after applying three different maneuvers in random order: (1) a PEEP of $10 \mathrm{cmH}_{2} \mathrm{O}(\mathrm{S} 10)$, (2) a $10^{\circ}$ Trendelenburg tilt position (T0), and (3) a $10^{\circ}$ Trendelenburg tilt position combined with a PEEP of $10 \mathrm{cmH}_{2} \mathrm{O}$ (T10). Using the images when the area was smallest and largest, crosssectional area (CSA), anteroposterior diameter, and transverse diameter were measured.

Results: All maneuvers minimized the fluctuation in RIJV size (all $\mathrm{P}=0.0004$ ). During the respiratory cycle, the smallest CSA compared to the largest CSA at S0, S10, T0, and T10 decreased by $28.38 .5,8.0$, and 4.4\%, respectively. Furthermore, compared to S0, a $10^{\circ}$ Trendelenburg tilt position with a PEEP of $10 \mathrm{cmH}_{2} \mathrm{O}$ significantly increased the CSA in the largest areas by $83.8 \%$ and in the smallest areas by $169.4 \%$.

Conclusions: A $10^{\circ}$ Trendelenburg tilt position combined with a PEEP of $10 \mathrm{cmH}_{2} \mathrm{O}$ not only increases the size of the RIJV but also reduces fluctuation by the respiratory cycle. (Korean J Anesthesiol 2014; 66: 346-351)

Key Words: Cross-sectional area, Internal jugular vein, Positive end-expiratory pressure, Trendelenburg position.

Received: September 17, 2013. Revised: October 14, 2013. Accepted: October 15, 2013.

Corresponding author: Sang Chul Lee, M.D., Ph.D., Department of Anesthesiology and Pain Medicine, Seoul National University Hospital, Seoul National University College of Medicine, 101, Daehak-ro, Jongno-gu, Seoul 110-744, Korea. Tel: 82-2-2072-2460, Fax: 82-2 747-5639, E-mail: sangclee@snu.ac.kr

(c) This is an open-access article distributed under the terms of the Creative Commons Attribution Non-Commercial License (http:// creativecommons.org/licenses/by-nc/3.0/), which permits unrestricted non-commercial use, distribution, and reproduction in any medium, provided the original work is properly cited. 


\section{Introduction}

Central venous catheterization utilizing anatomical landmarks via the right internal jugular vein (RIJV) is successful in most cases, and it offers the advantage of a linear course directed towards the right atrium [1]. However, this commonly performed maneuver is not without complications, most of which are associated with direct trauma from needling. The most common complication is accidental carotid artery puncture (reported incidence, 1.9-15\%) [1,2], which can cause airway obstruction due to hematoma formation [3]. Secondary complications include thromboembolism and arteriovenous fistula formation [4-6]. The incidence of such complications is directly related to the number of needling attempts during central venous catheterization $[7,8]$.

Having a large internal jugular vein (IJV) can increase the success rate of first pass attempts [9]; thus, several investigators have proposed methods to engorge the vein. Hollenbeck et al. [10] achieved an increase in RIJV cross-sectional area (CSA) by applying a positive-end expiratory pressure (PEEP) of 10 $\mathrm{cmH}_{2} \mathrm{O}$ in patients under general anesthesia, while Marcus et al. [11] studied the degree of increase in RIJV CSA following the application of 5 and $10 \mathrm{cmH}_{2} \mathrm{O}$ PEEP, with or without $20^{\circ}$ of Trendelendburg tilting. These studies measured the RIJV CSA at its largest, without considering changes in CSA according to the respiratory cycle. The IJV CSA is affected by respiratory fluctuations, and, theoretically, these differences are greater in patients under positive pressure ventilation. As the majority of central venous catheterizations in perioperative settings are performed on patients under positive pressure ventilation $[12,13]$, it is worth investigating the effects of respiratory fluctuations on the IJV CSA.

The purpose of this study was to investigate changes in the size (e.g., CSA, anteroposterior [AP] diameter, and transverse diameter) of the RIJV with respect to the respiratory cycle in patients under general anesthesia and positive pressure ventilation. We also examined the effects of PEEP and the Trendelenburg position on the size of the RIJV during the respiratory cycle.

\section{Materials and Methods}

This prospective, single blind and experimental study was approved by the Institutional Review Board. Written informed consent was obtained from all subjects. We enrolled 24 American Society of Anesthesiologists physical status I-II patients undergoing elective gynecologic or orthopedic surgery under general endotracheal anesthesia. The exclusion criteria were a history of neck surgery, previous RIJV cannulation, cardiac disease, and pulmonary disease. Patients were excluded after enrollment if severe hypotension after the induction of anesthesia occurred.

No other opioid or sedative premedication was administered. Routine monitoring of the subjects' blood pressure, an electro- cardiogram, and pulse oximetry were performed. Anesthesia was induced with propofol and remifentanil using a targetcontrolled infusion system (Orchestra ${ }^{\circledR}$ Base Primea; Fresenius Vial, Brezins, France). Neuromuscular blockade was performed with rocuronium $(0.6 \mathrm{mg} / \mathrm{kg})$. Following tracheal intubation, patients were placed on mechanically controlled ventilation (volume-controlled mode). Ventilation was set at 6-8 $\mathrm{ml} / \mathrm{kg}$ for the tidal volume, a respiratory rate of 10 breaths per minute at an inspiration-to-expiration time ratio of $1: 2$, and an end tidal carbon dioxide level of $30-40 \mathrm{mmHg}$. The ventilator settings were fixed while performing the study.

With the patient in the supine position, $\mathrm{PEEP}=0(\mathrm{~S} 0)$, and no head rotation, a high-frequency linear array transducer (LOGIQe; GE Medical, Jiangsu, China) was used to acquire a sufficient sonographic image of the RIJV by placing the probe perpendicularly over the skin at the cricoid cartilage level (longitudinal plane) with minimal pressure applied. Depending on the ventilation, the RIJV varied in size; the image was frozen and stored when the largest and smallest areas were shown. Whilst holding the probe in the same position, the RIJV was imaged following the application of three different maneuvers in random order: (1) a PEEP of $10 \mathrm{cmH}_{2} \mathrm{O}(\mathrm{S} 10)$, (2) a $10^{\circ}$ Trendelenburg position (T0), and (3) a PEEP of $10 \mathrm{cmH}_{2} \mathrm{O}$ and a $10^{\circ}$ Trendelenburg position (T10). Images of the RIJV were obtained at least $30 \mathrm{~s}$ after each maneuver, and in between the maneuvers, a minimum of $30 \mathrm{~s}$ interval was given at S0 (Fig. 1). The operating table was tilted $10^{\circ}$ to a Trendelenburg position using the Clinometer HD (plaincode $^{\mathrm{TM}}$, Schloßberg, Germany) Smartphone application.

The circumference of the RIJV was measured using an electronic marker, and an ultrasound unit was used to calculate the CSA. The examiner was blinded during the procedure. Using the ultrasound unit's embedded measuring system, the transverse (lateral to medial border of the wall) and AP (inferior to superior border of the wall) diameters of the vein were measured.

The patients' hemodynamics were monitored throughout the study. A 30\% decrease in systolic blood pressure below the baseline value was defined as hypotension; upon occurrence, patients were treated immediately with $5 \mathrm{mg}$ of ephedrine. A heart rate below 45 beats per minute was promptly raised by administering $0.5 \mathrm{mg}$ of atropine. The use of vasoactive drugs was recorded along with the patients' systolic blood pressure and heart rate. All subjects fasted for $8 \mathrm{~h}$ prior to the operation and received lactated Ringer's solution over the first hour $(4 \mathrm{ml} / \mathrm{kg})$.

The primary outcome measure was the difference in CSA of the RIJV at the largest and smallest measurements during S0, S10, T0, and T10. The secondary outcome measures were the differences between the transverse and AP diameters at the largest and smallest points during S0, S10, T0, and T10. We also examined the systolic blood pressure and heart rate of the subjects in each position. 

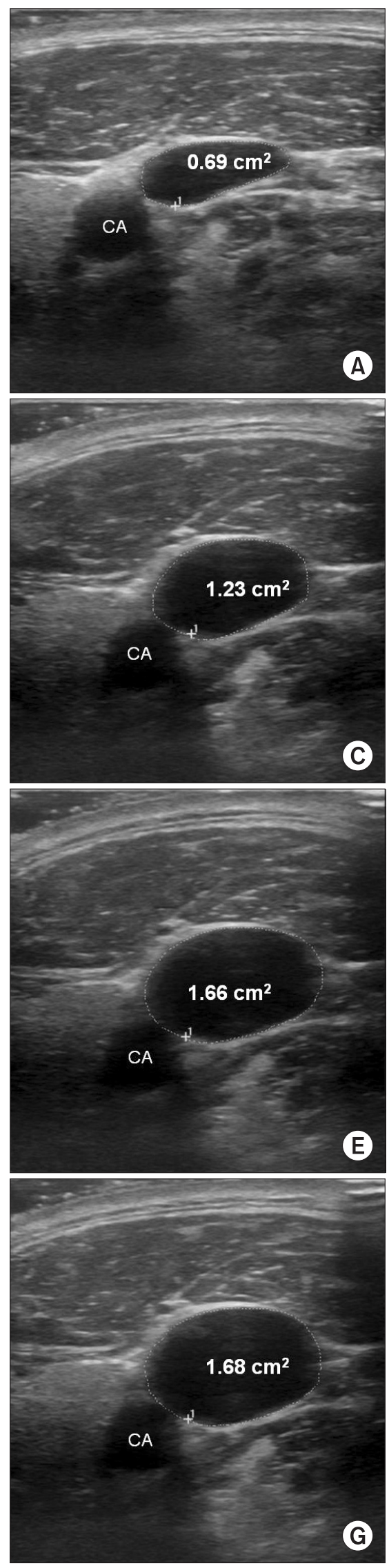

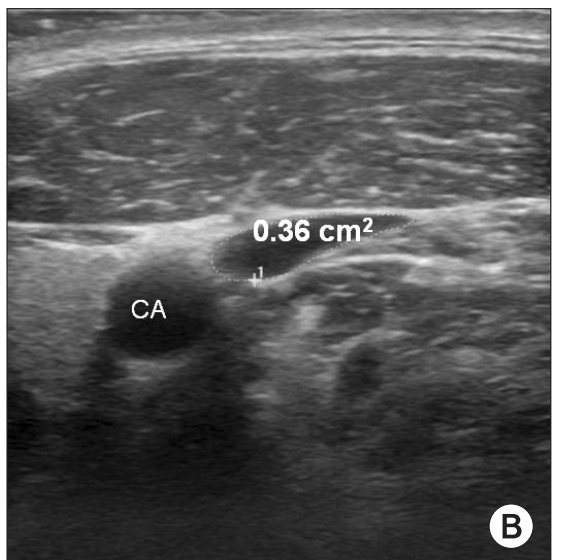

B
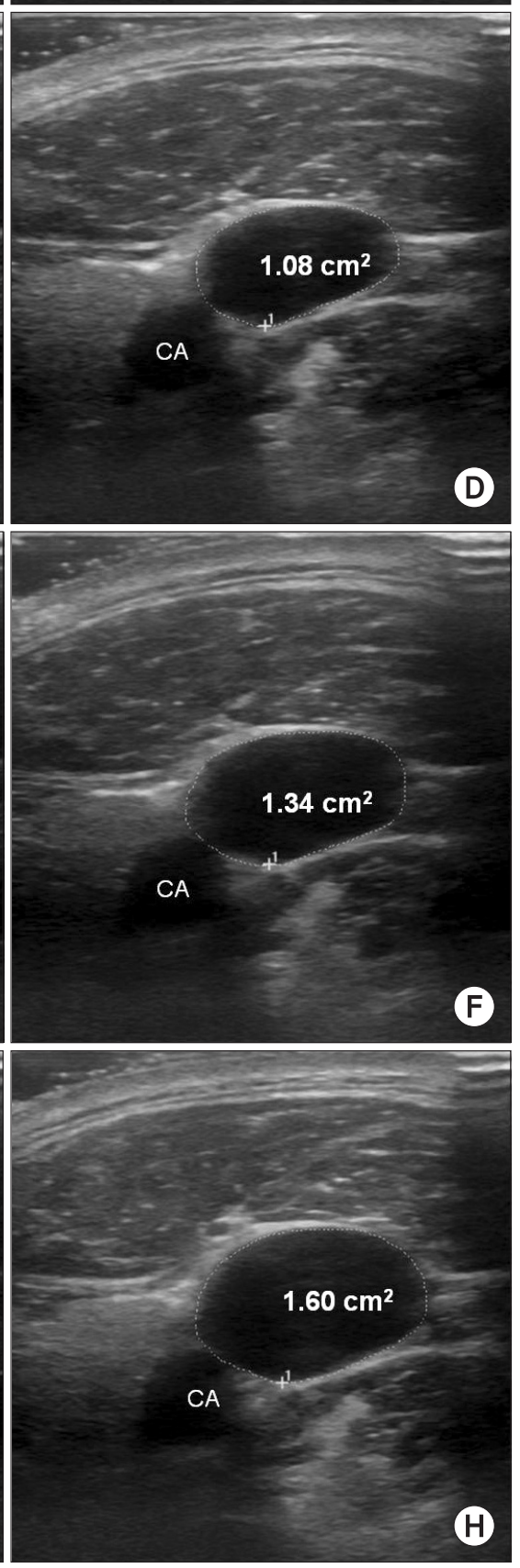

Fig. 1. Ultrasound images of the right internal jugular vein from one patient in four different maneuver combinations for the largest and smallest sizes recorded. Largest cross-sectional area measured during S0 (A), S10 (C), T0 (E) and T10 (G), respectively. Smallest cross-sectional area measured during S0 (B), S10 (D), T0 (F) and T10 (H). CA: carotid artery, Max: largest values during a respiratory cycle, Min: smallest values during a respiratory cycle, S0: supine baseline, S10: a positive-end expiratory pressure (PEEP) of $10 \mathrm{cmH}_{2} \mathrm{O}$, T0: a $10^{\circ}$ Trendelenburg tilt position, T10: a $10^{\circ}$ Trendelenburg tilt position combined with a PEEP of $10 \mathrm{cmH}_{2} \mathrm{O}$. 


\section{Statistics}

Randomization was achieved using the Orthoganol Latin Square Design method [14]. In each of the six sequences in the Orthogonal Latin Square Design, four patients were randomly assigned. One of the six sequences was randomly selected. Upon initiation of the study protocol, both PEEP and the Trendelenburg position were performed according to the order of the randomly assigned sequence.

SAS version 9.1 (SAS Institute, Cary, NC, USA) was used for all analyses. The statistical significance of the respiratory change in the RIJV CSA, and the transverse and AP diameters were analyzed using Generalized Estimating Equation analysis. The $P$ values obtained using these models were adjusted using the Hochberg method. The statistical significance of the changes (largest and smallest, respectively) in the CSA of the RIJV, and the transverse and AP diameters following the application of the different maneuvers was analyzed using a mixed model. The $P$ values obtained using this model were adjusted using Scheffés method. $\mathrm{P}<0.05$ was considered statistically significant.

The largest and smallest CSAs at S0 and S10 from ten patients were collected; the mean and standard deviation of the variation

Table 1. Demographic and Baseline Information $(n=24)$

\begin{tabular}{lc}
\hline Characteristic & Mean \pm SD \\
\hline Age $(\mathrm{yr})$ & $43.5 \pm 12.7$ \\
Gender $(\mathrm{M}: \mathrm{F})$ & $7(29): 17(71)$ \\
Height $(\mathrm{cm})$ & $160.4 \pm 9.6$ \\
Weight $(\mathrm{kg})$ & $61.4 \pm 10.6$ \\
BMI $\left(\mathrm{kg} / \mathrm{m}^{2}\right)$ & $23.9 \pm 3.3$ \\
IJV depth $(\mathrm{cm})$ & $1.13 \pm 0.2$ \\
\hline
\end{tabular}

Data are expressed as mean \pm SD or number (\%). BMI: body mass index, IJV: internal jugular vein. in CSA was used to determine the sample size. In a pilot study of ten subjects, the average changes in S0 and S10 were $0.34 \pm 0.18$ and $0.16 \pm 0.11$ (mean \pm SD), respectively. A minimum sample size of 22 was calculated using $\alpha=0.05$, a power of $90 \%$, and $20 \%$ dropout. Thus, a sample size of 24 patients was required to incorporate the Prescott triple Latin square design [14].

\section{Results}

The patient characteristics are shown in Table 1. Seven of the patients were male (29\%) and 17 were female (71\%). Most of the females were gynecology patients. Complete data and images suitable for analysis were obtained for all patients. No complications were encountered.

Table 2 shows the changes in CSA, transverse diameter, and AP diameter for the largest and smallest RIJV according to the position or PEEP application and the difference between inspiration and expiration. The combination of the two maneuvers (T10) produced a $4.4 \%$ decrease in the CSA respiratory change in the RIJV from a $28.3 \%$ decrease at baseline (S0) (P = 0.0004; GEE analysis). The effect of PEEP and the Trendelenburg position alone on the respiratory change-induced decrease in CSA of the RIJV was 8.5 and $8.0 \%$, respectively (all $\mathrm{P}=0.0004$; GEE analysis). In all patients, the CSA, transverse diameter, and AP diameter of the largest and smallest RIJV increased with PEEP application, Trendelenburg position, and both treatments combined.

The systolic blood pressure decreased significantly by 7.0 $\mathrm{mmHg}$, following the application of $10 \mathrm{cmH}_{2} \mathrm{O}$ PEEP $(\mathrm{P}=0.024$; GEE analysis) (Table 3 ). In a $10^{\circ}$ Trendelenburg position (T0) and a PEEP of $10 \mathrm{cmH}_{2} \mathrm{O}$ and a $10^{\circ}$ Trendelenburg position (T10), the heart rate decreased significantly with the Trendelenburg position $(\mathrm{P}=0.0005$ and $\mathrm{P}=0.004$, respectively; GEE

Table 2. Right Internal Jugular Vein Measurements

\begin{tabular}{|c|c|c|c|c|}
\hline & So & S10 & T0 & $\mathrm{T} 10$ \\
\hline \multicolumn{5}{|c|}{ CSA $\left[\mathrm{cm}^{2}(\%\right.$ increase $\left.)\right]$} \\
\hline $\operatorname{Max}\left(\mathrm{cm}^{2}\right)$ & $1.36 \pm 0.63$ & $1.92 \pm 0.69(51.7)^{*}$ & $2.07 \pm 0.79(65.2)^{*}$ & $2.25 \pm 0.76(83.8)^{*, \dagger}$ \\
\hline $\operatorname{Min}\left(\mathrm{cm}^{2}\right)$ & $1.04 \pm 0.62$ & $1.77 \pm 0.69(108.6)^{*}$ & $1.92 \pm 0.74(128.1)^{*}$ & $2.14 \pm 0.69(169.4)^{*, \dagger, \dagger}$ \\
\hline Min-Max (\%) & $\downarrow 28.3$ & $\downarrow 8.5^{*}$ & $\downarrow 8.0^{*}$ & $\downarrow 4.4^{*, \dagger, \neq}$ \\
\hline \multicolumn{5}{|c|}{ AP diameter $[\mathrm{cm}$ (\% increase $)]$} \\
\hline $\operatorname{Max}(\mathrm{cm})$ & $0.99 \pm 0.29$ & $1.29 \pm 0.27(35.9)^{*}$ & $1.35 \pm 0.28(43.3)^{*}$ & $1.42 \pm 0.25(51.6)^{*, \dagger}$ \\
\hline $\operatorname{Min}(\mathrm{cm})$ & $0.82 \pm 0.34$ & $1.23 \pm 0.29(72.2)^{*}$ & $1.29 \pm 0.29(81.5) *$ & $1.39 \pm 0.24(100.3)^{*, \dagger, †}$ \\
\hline Min-Max (\%) & $\downarrow 20.8$ & $\downarrow 5.1^{*}$ & $\downarrow 5.4^{*}$ & $\downarrow 2.4^{*, \dagger, \neq}$ \\
\hline \multicolumn{5}{|c|}{ Transverse diameter $[\mathrm{cm}$ (\% increase)] } \\
\hline $\operatorname{Max}(\mathrm{cm})$ & $1.71 \pm 0.36$ & $1.85 \pm 0.35(9.3)^{*}$ & $1.90 \pm 0.36(12.5)^{*}$ & $1.98 \pm 0.37(16.9)^{*, \dagger}$ \\
\hline $\operatorname{Min}(\mathrm{cm})$ & $1.54 \pm 0.37$ & $1.79 \pm 0.34(18.5)^{*}$ & $1.86 \pm 0.36(23.5)^{*}$ & $1.94 \pm 0.36(28.9)^{*, \dagger}$ \\
\hline Min-Max (\%) & $\downarrow 10.3$ & $\downarrow 3.2 *$ & $\downarrow 2.1^{*}$ & $\downarrow 1.9^{*}$ \\
\hline
\end{tabular}

Data are expressed as mean \pm SD or percentage (\%). AP: anteroposterior, CSA: cross-sectional area $\left(\mathrm{cm}^{2}\right)$, Increase (\%): percent increase from supine baseline (S0), Max: largest values during a respiratory cycle, Min: smallest values during a respiratory cycle, Min-Max (\%): $\downarrow[($ Min-Max)/Max $\times 100$, PEEP: positive end-expiratory pressure, S0: supine baseline, S10: a PEEP of $10 \mathrm{cmH}_{2} \mathrm{O}$, T0: a $10^{\circ}$ Trendelenburg tilt position, T10: a $10^{\circ}$ Trendelenburg tilt position combined with a PEEP of $10 \mathrm{cmH}_{2} \mathrm{O} . * \mathrm{P}<0.001$ compared with $\mathrm{S} 0 .{ }^{\dagger} \mathrm{P}<0.05$ compared with $\mathrm{S} 10 .{ }^{\dagger} \mathrm{P}<0.05$ compared with $\mathrm{T} 0$. 
Table 3. Hemodynamic Change

\begin{tabular}{lcccc}
\hline & S0 & S10 & T0 & T10 \\
\hline SBP (mmHg) & $115.6 \pm 16.7$ & $108.6 \pm 18.9^{*}$ & $110.6 \pm 15.7^{*}$ & $113.1 \pm 15.8$ \\
HR (beats/min) & $70.3 \pm 12.1$ & $70.0 \pm 14.9$ & $65.0 \pm 9.2^{\dagger}$ & $66.4 \pm 13.3^{\dagger}$ \\
\hline
\end{tabular}

Data are expressed as mean \pm SD. SBP: systolic blood pressure, HR: heart rate, S0: supine baseline, S10: a positive-end expiratory pressure (PEEP) of $10 \mathrm{cmH}_{2} \mathrm{O}$, T0: a $10^{\circ}$ Trendelenburg tilt position, T10: a $10^{\circ}$ Trendelenburg tilt position combined with a PEEP of $10 \mathrm{cmH}_{2} \mathrm{O}$. $* \mathrm{P}<0.05,{ }^{\dagger} \mathrm{P}<0.01$ compared with S0.

analysis) (Table 3). In addition, no requirement for ephedrine or atropine due to hypotension or bradycardia occurred during the study period.

\section{Discussion}

This study was designed to evaluate the effect of the respiratory cycle on the size of the RIJV and to determine the impact of PEEP and the Trendelenburg position in anesthetized adult patients under positive pressure ventilation. During positive pressure ventilation, the CSA was its largest at inspiration and smallest at expiration, with a mean decrease in size from largest to smallest of $28.3 \pm 14.7 \%$. Furthermore, with either the Trendelenburg position or PEEP application, this difference was reduced. When combined, the difference decreased further; the largest and smallest CSAs were $2.25 \pm 0.76$ and $2.14 \pm 0.69 \mathrm{~cm}^{2}$, respectively.

Ultrasound-guided RIJV puncture compared to regular RIJV puncture resulted in a lower number of puncture attempts, a higher success rate, and an increased chance of a successful puncture on the first attempt, thus reducing complications [15-17]. Nonetheless, ultrasound-guided IJV cannulation caused certain complications, the most frequent being carotid artery puncture at a rate of $1.4 \%$ [18]. To reduce complications, numerous studies have sought to create a method for increasing vein size [19-21]. Placing the patient at Trendelenburg positions and using the valsalva maneuver, inspiratory hold, and PEEP can increase the size of the IJV [10-12,15,19-22]. However, previous studies focused only on maximizing the vein size, without considering changes in size according to the respiratory cycle.

To minimize complications such as carotid artery puncture, it is recommended to maximize the IJV diameter by controlled ventilation at end-inspiration which reduces the collapsibility of the vein during puncture; thus, the maneuver ultimately reduces any unnecessary additional advancement of the needle during central venous catheterization procedure, lowering the chance of artery puncture [13]. Because attempting insertion of the needle during spontaneous ventilation by synchronized timing according to respiratory cycle would be rather difficult, the authors suggest to insert the needle after induction rather than before, timing puncture at end-inspiration after intermittent positive ventilation [13]. Our study showed that both the Trendelenburg position and PEEP application not only increased the size of the vessel, but also reduced fluctuations in size caused by the respiratory cycle. The two in combination resulted in a more effective decrease in fluctuations according to the respiratory cycle; hence, a synchronized puncture according to the respiratory cycle would not be necessary.

Our study used several parameters to determine the size of the IJV: CSA, AP diameter, and transverse diameter. Previous studies have described increases in diameter, but the vein was ovoid rather than round [20,21]. Thus, the term diameter is vague and cannot distinguish between the AP and transverse diameters. Our study shows that use of the Trendelenburg position or PEEP application alone minimally changed the transverse diameter while increasing the AP diameter to increase the CSA. This increase reduced the possibility of transfixation caused by needle pressure while puncturing the vein [12,23], leading to a reduced likelihood of posterior wall puncture and a reduced chance of carotid artery puncture [9]. If the transverse diameter had been used in previous studies, the results could have been underestimated. Therefore, the study's primary outcome was set to the change in CSA, and to determine whether the change in CSA was due to the transverse diameter or AP diameter. Changes in the transverse diameter and AP diameter were set as secondary outcomes. Our results indicate that the Trendelenburg position and/or PEEP application increased the CSA, mainly by increasing the AP diameter.

Clenaghan et al. [21] studied the change in RIJV diameter in healthy subjects in different Trendelenburg positions $(10,15,20$, 25 , and $30^{\circ}$ ). The authors reported that even a $10^{\circ}$ tilt is effective while a $25^{\circ}$ Trendelenburg tilt achieved the optimum distension. The authors recommended using a $10^{\circ}$ tilt. Lobato et al. [12] found that a $10^{\circ}$ Trendelenburg position increased the RIJV CSA by $25 \%$ and further increase combining hepatic compression and/or inspiratory hold while a $20^{\circ}$ Trendelenburg position resulted in no further increase. Moreover, the degree of PEEP used in the current study was based on previous studies, which showed that PEEPs of a PEEP of $10 \mathrm{cmH}_{2} \mathrm{O}$ increased the CSA of the right internal jugular vein by 22.3 and $41.0 \%$, respectively $[10,11]$. Accordingly, we chose a $10^{\circ}$ Trendelenburg tilt and a PEEP of $10 \mathrm{cmH}_{2} \mathrm{O}$.

Two major limitations are evident in this study. First, changes in IJV CSA are directly related to successful cannulation. The 
hypothesis that a larger target vessel size would increase the success rate of line placement was supported, but not proven, by this study. Second, the observers were not blinded to the maneuvers. However, the order in which the three maneuvers were applied was randomized, and a blinded examiner measured the CSA and transverse and AP diameters using stored images.

A $10^{\circ}$ Trendelenburg tilt position combined with a PEEP of $10 \mathrm{cmH}_{2} \mathrm{O}$ reduced respiratory fluctuations in the RIJV; specifically, it decreased the mean difference in CSA, AP diameter, and transverse diameter during the respiratory cycle by $4.4,2.4$, and $1.9 \%$, respectively, compared with the baseline $(28.3,20.8$, and $10.3 \%)$. Moreover, the combination of the two caused no decrease in systolic blood pressure from baseline. To minimize fluctuations in RIJV size according to the respiratory cycle, and to maximally increase its size, we recommend a $10^{\circ}$ Trendelenburg tilt position combined with a PEEP of $10 \mathrm{cmH}_{2} \mathrm{O}$ during needle insertion for cannulation of the RIJV under positive pressure ventilation.

\section{References}

1. Miller RD. Miller's anesthesia. 7th ed. New York, Churchill Livingstone. 2009, pp 1285-6.

2. Shah KB, Rao TL, Laughlin S, El-Etr AA. A review of pulmonary artery catheterization in 6,245 patients. Anesthesiology 1984; 61: 271-5.

3. Goldfarb G, Lebrec D. Percutaneous cannulation of the internal jugular vein in patients with coagulopathies: an experience based on 1,000 attempts. Anesthesiology 1982; 56: 321-3.

4. Heath KJ, Woulfe J, Lownie S, Pelz D, Munoz DG, Mezon B. A devastating complication of inadvertent carotid artery puncture. Anesthesiology 1998; 89: 1273-5.

5. Reuber M, Dunkley LA, Turton EP, Bell MD, Bamford JM. Stroke after internal jugular venous cannulation. Acta Neurol Scand 2002; 105: 235-9.

6. Sharma VK, Pereira AW, Ong BK, Rathakrishnan R, Chan BP, Teoh HL. Images in cardiovascular medicine. External carotid artery-internal jugular vein fistula: a complication of internal jugular cannulation. Circulation 2006; 113: e722-3.

7. McGee DC, Gould MK. Preventing complications of central venous catheterization. N Engl J Med 2003; 348: 1123-33.

8. Mansfield PF, Hohn DC, Fornage BD, Gregurich MA, Ota DM. Complications and failures of subclavian-vein catheterization. N Engl J Med 1994; 331: 1735-8.

9. Gordon AC, Saliken JC, Johns D, Owen R, Gray RR. US-guided puncture of the internal jugular vein: complications and anatomic considerations. J Vasc Interv Radiol 1998; 9: 333-8.

10. Hollenbeck KJ, Vander Schuur BM, Tulis MR, Mecklenburg BW, Gaconnet CP, Wallace SC, et al. Brief report: effects of positive endexpiratory pressure on internal jugular vein cross-sectional area in anesthetized adults. Anesth Analg 2010; 110: 1669-73.

11. Marcus HE, Bonkat E, Dagtekin O, Schier R, Petzke F, Wippermann J, et al. The impact of Trendelenburg position and positive endexpiratory pressure on the internal jugular cross-sectional area. Anesth Analg 2010; 111: 432-6.

12. Lobato EB, Florete OG Jr, Paige GB, Morey TE. Cross-sectional area and intravascular pressure of the right internal jugular vein during anesthesia: effects of Trendelenburg position, positive intrathoracic pressure, and hepatic compression. J Clin Anesth 1998; 10: 1-5.

13. Manikappa S, Cokis C. Assessment of internal diameter and cross-sectional area of right internal jugular vein pre-induction and postintubation. Anaesth Intensive Care 2005; 33: 381-3.

14. Jones B, Kenward MG. Design and Analysis of Cross-Over Trials. 2nd ed. London, Chapman and Hall/CRC. 2003, pp 162-3.

15. Denys BG, Uretsky BF, Reddy PS. Ultrasound-assisted cannulation of the internal jugular vein. A prospective comparison to the external landmark-guided technique. Circulation 1993; 87: 1557-62.

16. Mallory DL, McGee WT, Shawker TH, Brenner M, Bailey KR, Evans RG, et al. Ultrasound guidance improves the success rate of internal jugular cannulation. A prospective, randomized trial. Chest 1990; 98: 157-60.

17. Koski EM, Suhonen M, Mattila MA. Ultrasound-facilitated central venous cannulation. Crit Care Med 1992; 20: 424-6.

18. Mey U, Glasmacher A, Hahn C, Gorschlüter M, Ziske C, Mergelsberg M, et al. Evaluation of an ultrasound-guided technique for central venous access via the internal jugular vein in 493 patients. Support Care Cancer 2003; 11: 148-55.

19. Verghese ST, Nath A, Zenger D, Patel RI, Kaplan RF, Patel KM. The effects of the simulated Valsalva maneuver, liver compression, and/or Trendelenburg position on the cross-sectional area of the internal jugular vein in infants and young children. Anesth Analg 2002; 94: 250-4.

20. Armstrong PJ, Sutherland R, Scott DH. The effect of position and different manoeuvres on internal jugular vein diameter size. Acta Anaesthesiol Scand 1994; 38: 229-31.

21. Clenaghan S, McLaughlin RE, Martyn C, McGovern S, Bowra J. Relationship between Trendelenburg tilt and internal jugular vein diameter. Emerg Med J 2005; 22: 867-8.

22. Lee SC, Han SS, Shin SY, Lim YJ, Kim JT, Kim YH. Relationship between positive end-expiratory pressure and internal jugular vein crosssectional area. Acta Anaesthesiol Scand 2012; 56: 840-5.

23. Tercan F, Oguzkurt L, Ozkan U, Eker HE. Comparison of ultrasonography-guided central venous catheterization between adult and pediatric populations. Cardiovasc Intervent Radiol 2008; 31: 575-80. 